\title{
Development and validation of a mental health screening tool for asylum-seekers and refugees: the STAR-MH
}

\author{
Debbie C. Hocking ${ }^{1,2,4^{*}}$, Serafino G. Mancuso ${ }^{3}$ and Suresh Sundram²,3,4,5
}

\begin{abstract}
Background: There is no screening tool for major depressive disorder (MDD) or post-traumatic stress disorder (PTSD) in asylum-seekers or refugees (ASR) that can be readily administered by non-mental health workers. Hence, we aimed to develop a brief, sensitive and rapidly administrable tool for non-mental health workers to screen for MDD and PTSD in ASR.
\end{abstract}

Methods: The screening tool was developed from an extant dataset $(n=121)$ of multiply screened ASR and tested prospectively $(N=192)$ against the M.I.N.I. (Mini International Neuropsychiatric Interview) structured psychiatric interview. Rasch, Differential Item Functioning and ROC analyses evaluated the psychometric properties and tool utility.

Results: A 9-item tool with a median administration time of six minutes was generated, comprising two 'immediate screen-in' items, and a 7-item scale. The prevalence of PTSD \&/or MDD using the M.I.N.I. was 32\%, whilst 99\% of other diagnosed mental disorders were comorbid with one or both of these. Using a cut-score of $\geq 2$, the tool provided a sensitivity of 0.93 , specificity of 0.75 and predictive accuracy of $80.7 \%$.

Conclusions: A brief sensitive screening tool with robust psychometric properties that was easy to administer at the agency of first presentation was developed to facilitate mental health referrals for asylum-seekers and new refugees.

Keywords: Asylum-seekers, Refugees, Mental health screening, Tool development, Post-traumatic stress disorder, Depression

\section{Background}

The world currently has the largest number of displaced persons at any time in history [1]. This has seen increasing numbers of forced migrants entering industrialised countries [1], intensifying the challenge to efficiently screen health conditions. In most countries asylum-seekers are not screened for mental health problems at any point during the asylum process [2], which is similarly the case for a large proportion of newly resettled refugees [3-7].

Compounding this is the knowledge that forced migrant populations have high rates of mental disorders, with major depressive disorder (MDD) and post-traumatic stress disorder (PTSD) in particular being many fold higher than in host [8] and non-forced migrant populations [9]. A large

\footnotetext{
* Correspondence: debbie.hocking@florey.edu.au

${ }^{1}$ Cabrini Institute, 154 Wattletree Road, Malvern, VIC 3144, Australia

${ }^{2}$ Florey Institute of Neuroscience and Mental Health, 30 Royal Parade (Cnr

Genetics Lane), Parkville, VIC 3052, Australia

Full list of author information is available at the end of the article
}

meta-analysis of refugees and other conflict-affected persons reported adjusted weighted prevalence rates of $30 \%$ for MDD and PTSD [10], suggesting these to be the most widespread mental disorders in this population with even higher rates reported in asylum-seekers [11-14].

The burgeoning number of displaced persons globally and their disproportionately high rates of mental disorders have prompted the World Health Organisation (WHO) to call upon treatment services to be responsive to the needs of asylum-seekers and refugees [15]. Yet, utilisation of mental health services is comparatively low in this population [16] for reasons including lack of accessibility, poverty, poor language comprehension, lack of knowledge of services, cultural factors and stigma [4]. Furthermore, increasingly time-constrained agencies have to contend with increasing need whilst grappling with limited human resources. Several of these issues could be addressed by the availability of a brief, sensitive and rapidly administrable screening tool by 
non-mental health workers which would facilitate triaging of asylum seekers and refugees with mental health problems to be referred to an appropriate health service.

Extant mental health screening tools do not fully meet these aforementioned criteria with several well-utilised tools having a number of drawbacks. These include not being validated in forced migrant populations (e.g., K10, K6, BAI, DASS-21, PTSD-8, GHQ-12) [17, 18]; too prolonged to facilitate rapid screening of large populations (e.g., DASS-21, RHS-15; HSCL-25; HTQ); screening for distress rather than disorder and lacking predictive validity against a standardised psychiatric interview (e.g., K10; RHS-15; WHO-5; SRQ-20) [19]; or screening for either MDD or PTSD - not both [20, 21].

Despite being one of the more commonly used screening tools for depression and anxiety, a recent review raised concerns about the lack of evidence for the validity and cultural equivalence of the K10, including variation between ethnic/ linguistic groups for studies with multicultural samples [17]. The SRQ-20 was developed to screen for psychiatric disturbance, but primarily for those in developing countries, and has not established its predictive validity against a standardised psychiatric interview [19]. Whilst the RHS-15 [3] was developed for refugee populations, it was designed to be administered in clinical settings, and has not been validated in asylum-seeker populations or against an acceptable gold standard [3].

A high proportion of mental disorders in the general population go undetected by healthcare professionals in the course of their routine work [22-24] and it would be predicted that non-mental health trained workers would be even less likely to identify possible mental disorders in their forced migrant clients. Consequently, we strove to develop a screening instrument that could be utilised by non-mental health workers across a variety of contexts, to minimise administrator-burden whilst increasing the likelihood of client uptake. To maximise the utility of such an instrument, it also would need to have efficacy in linguistically diverse and potentially under-resourced settings, using interpreters rather than undertaking multiple translations.

The present paper reports on the development and validation of a brief screening tool for PTSD and MDD in adult asylum-seekers and refugees (STAR-MH) that is suitable for use by non-mental health workers.

\section{Methods}

\section{Procedure}

A visual overview of the data sampling process is presented in Fig. 1 which comprise a derivation sample - from which the initial 12-items scale was derived, and two pilot samples (for the initial 12-item version, and subsequent 10 -item versions). The final version was a 9-item scale, which forms the basis of the Results section.
All administrators of the STAR-MH were briefed prior to each pilot study on the importance of adhering to the research protocol (such as delivering each item neutrally, without elaboration; providing written feedback on the process) and instructed about risk management processes should the need arise. Administrators were accustomed to working with interpreters. The tool itself was designed to be sufficiently simple to not require specific training to administer.

Given the purpose was to develop a mental health screening tool for forced migrants, participants were unselected by country of origin. Hence, the tool was not translated, but instead utilised in situ translation by professional telephone or face-to-face interpreters in the language required by participants as they consecutively presented to the recruiting agency.

The STAR-MH items were derived from scales considered to be gold standard instruments for measuring symptoms of depression, anxiety and PTSD in individuals of refugee-like background.

Community leaders from the cultural and linguistic communities with the greatest numbers of forced migrants in Australia (Sri Lankan/Tamil; Iranian/Farsi and Afghan/ Dari) were consulted to ascertain the cultural appropriateness and utility of the tool.

\section{Derivation sample}

The initial 12-item version of the STAR-MH [25], was derived from a sample of 56 ASR from a previous study [14] whom had completed four self-report questionnaires (Harvard Trauma Questionnaire-R, Parts I - trauma experiences \& IV - PTSD and refugee-specific symptoms, and Hopkins Symptom Checklist-25 [26]; Post-Migration Living Difficulties Checklist [27]; and Psychiatric Epidemiology Research Interview-Demoralization Scale [28]) and the M.I.N.I. (Mini International Neuropsychiatric Interview) [29]. Scaled items from the four questionnaires were dichotomised, with values $\geq 3$ designating clinical relevance. All 153 items were then entered into chi-square analyses to establish the sensitivity $(\mathrm{SN})$ and specificity (SP) of each item against M.I.N.I diagnoses of PTSD and MDD. Only statistically significant items (Kappa statistic) were retained, resulting in 66 items.

Spearman's Rho correlations were then performed between the 66 items and PTSD and MDD diagnoses. All items with a correlation $\geq 0.7$ and a predictive accuracy of $\geq 0.85$ for PTSD and/or MDD were retained and after two items were discarded due to redundancy nine items remained. Three 'immediate screen-in' items were included on clinical grounds, resulting in an initial 12-item version of the screening tool. A quantitative and qualitative administrator feedback section was also included to inform the second iteration of the tool (data not shown). 

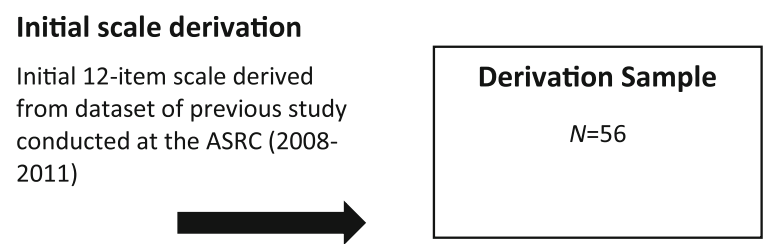

\section{First pilot}

STAR-MH v.1 (12-items)

Conducted at the ASRC
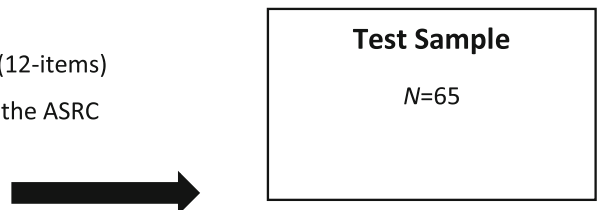

\section{Second pilot}

STAR-MH v.2 (10-items)

Conducted at the ASRC and Monash Health Refugee Health Clinic (MHC)

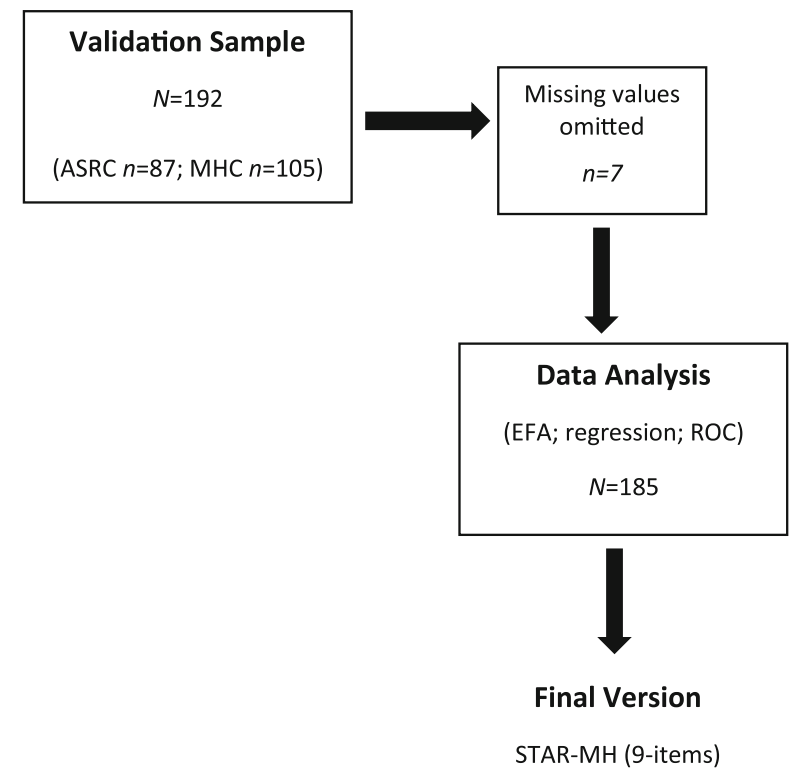

Fig. 1 Sampling and iterative development of the STAR-MH

\section{Test sample}

The initial 12-item version was evaluated at a community based asylum seeker welfare centre (Asylum Seeker Resource Centre, ASRC), with a consecutive sample of asylum-seekers $(N=65)$ being recruited through the (non-health) casework program. The sample was inclusive of adults ( $\geq 18$ years) recently engaged with the ASRC ( $\leq$ 6 months) who had not been diagnosed with or treated for a psychiatric disorder since arriving in Australia. Eight ASRC casework program volunteers from a range of nonmental health backgrounds, such as university students, administration, nurses and general practitioners (GP) were briefed on the research protocol for the tool. All screened participants were subsequently administered the M.I.N.I by a researcher $(\mathrm{DH})$, who was blind to the screening results. During the validation interview, demographic information was collected and participants were administered the HTQ-R (Part IV) and HSCL-25. Interpreters were utilised as necessary for both the screening and the validation interview.

Receiver operating characteristic (ROC) curve analyses were conducted on the 12 items with the test sample, resulting in five items being retained.

Given the objective was to identify likely caseness of either MDD or PTSD and because of the substantial comorbidity, both diagnoses were treated as a single outcome variable for the chi-square analyses below.

The statistical power was increased by pooling the derivation and test sample data. Hence, all 65 HTQ-R and HSCL-25 items were entered into chi-square analyses $(N=121)$ to ascertain the $\mathrm{SN}$ and SP of each item against M.I.N.I diagnoses of PTSD and MDD. Items with 
$\geq 85 \%$ SN and $\geq 75 \%$ SP were retained, resulting in 10 items in addition to those retained from the ROC analysis. Classification and Regression Tree (CART) analyses were then conducted for these 15 items with the total dataset $(N=121)$. This resulted in eight items being retained in addition to two of the original three 'immediate screen in items' from the chi-square analyses. The third 'immediate screen in' item was discarded due to poor predictive accuracy.

The resulting second iteration was a 10-item STAR$\mathrm{MH}$, the items of which are presented in Table 1, including the scales from which the items were derived.

\section{Validation sample}

The 10-item screening tool was piloted with consecutive sample populations of ASR at two sites in Victoria, Australia: the ASRC $(n=87)$, and Monash Health Community (MHC) (i.e., Refugee Health Clinic; Monash Health Dental Clinic) $(n=105)$. In addition, a representative sample of administrators was enlisted to test the external validity of the tool.

ASRC participants were recruited through the casework and health programs. The recruitment strategy from the casework program involved screening tool administrators contacting all ASRC 'general access-listed' clients to ascertain eligibility and conduct face-to-face screening with consenting individuals. Consecutive 'walk in' patients presenting to the health program (non-mental health) who were eligible and consented were variously screened by a nurse, GP or untrained ASRC volunteer. Similarly, eligible consecutive patients presenting to the $\mathrm{MHC}$ were screened by a bicultural worker, nurse, GP or interpreter. All administrators were briefed on the research protocol for the tool and interpreters were utilised as required.
All screened participants were subsequently administered the M.I.N.I by a research team member (DH), who was blind to all screening results, using interpreters as required.

\section{Instruments}

The mini international neuropsychiatric interview (M.I.N.I. 6.0) The Mini International Neuropsychiatric Interview 6.0 (M.I.N.I) [29] is a brief, structured psychiatric interview developed in the United States and Europe for assessing the presence of DSM-IV and ICD-10 psychiatric disorders. It has been found to have sound SN (i.e., $\geq 0.70$ for all but three of the modules), SP, negative predictive values and efficiency (i.e., $\geq$ of 0.85 across all diagnoses) when measured against the SCID [30]. Additionally, the majority of kappa values have been reported above 0.75 , indicating good test-retest reliability, with inter-rater reliability also found to be high when validated with the SCID (i.e., 0.79-1.00) [30].

The M.I.N.I was chosen as the diagnostic instrument by which to validate the STAR-MH due to its brevity of administration compared to the SCID and CIDI [30, 31]; and its application within forced migrant populations [2, 32-34]. All MINI modules were applied, with the exception of Antisocial Personality disorder and Anorexia and Bulimia Nervosa due to i) focusing on prevalence of mental illness and ii) eating disorders being exceedingly uncommon in adult refugee populations.

\section{Self-report measures}

Items from the above measures (Harvard Trauma Questionnaire-R; Hopkins Symptom Checklist-25; PostMigration Living Difficulties Checklist; and Psychiatric Epidemiology Research Interview-Demoralization Scale)

Table 1 Screening tool for asylum-seeker and refugee mental health (STAR-MH) items

\begin{tabular}{|c|c|c|}
\hline & STAR-MH Item & Scale derivation \\
\hline 1. & $\begin{array}{l}\text { Have you ever seen a doctor or health worker, gone to hospital, or taken } \\
\text { medicines for your 'nerves'? (i.e. mental or emotional health) }\end{array}$ & \\
\hline 2. ${ }^{a}$ & $\begin{array}{l}\text { Have you often wished you were dead, wanted to kill yourself or ever } \\
\text { attempted suicide or harmed yourself? }\end{array}$ & \\
\hline 3. $b$ & Have you felt very restless, like you can't keep still? & HSCL-10 (anxiety item) \\
\hline 4. & Have you lost interest in things? (i.e. things you usually enjoy) & HSCL-23 (depression item) \\
\hline 5. & Have you worried about going crazy or 'losing your mind'? & PERI-D-11 (also HTQ-24 d; trauma item) \\
\hline 6. ${ }^{c}$ & Have you had $\boldsymbol{a}$ lot of trouble sleeping? & HSCL-16 \& HTQ-8 (depression and trauma item) \\
\hline 7. & Have you felt very fearful? (i.e. scared or afraid) & HSCL-2 (anxiety item) \\
\hline 8. & $\begin{array}{l}\text { Have you felt very trapped or caught? (e.g. like you are trapped in a situation } \\
\text { you cannot get out of) }\end{array}$ & HSCL-21 (depression item) \\
\hline 9. & Have you had $\boldsymbol{a}$ lot of pain in your body? & HTQ-20 (refugee-specific trauma item) \\
\hline 10. & Have you felt very worthless? (i.e. like you have no worth or value) & HSCL-25 (depression item) \\
\hline
\end{tabular}

ammediate screen-in item

${ }^{b}$ Items 3-10 timeframe is the last 4 weeks

'Excluded from final 9-item scale

ditem from the original HTQ (Original Version) 
contributed a pool of responses for potential inclusion in iterations of the STAR-MH.

\section{Hopkins symptom Checklist-25 (HSCL-25)}

The HSCL-25 [26] is divided into two parts: anxiety symptoms (Part I, 10 items, questions 1-10) and depression symptoms (Part II, 15 items, questions 11-25), with the Total Scale measuring 'nonspecific emotional distress'. All items are coded 1 (not at all), 2 (a little), 3 (quite a bit) and 4 (extremely) indicating the degree of distress within the previous seven days.

The HSCL-25 has been translated into several languages [26] and used in many studies with forced migrant populations [35]. It was one of only two instruments adapted for refugee populations (the other was the Beck Depression Inventory) which met all five criteria (i.e., Purpose, Construct definition, Design, Developmental process, Reliability and validity) in a critical review of the validity and reliability of psychometric tools to measure mental health status in forced migrants [35]. Demonstrating very good predictive validity for diagnosed depression $(\mathrm{SN}=$ 0.88; $\mathrm{SP}=0.73$ ) [35], empirical studies have determined the depression items to be consistent with the DSM-IV diagnosis of major depression [26]. Furthermore, the HSCL-25 was found to have high SN (0.93) and SP (0.76) in detecting the presence of any major DSM-III-R-defined Axis I disorder in three Indochinese populations [36].

The HSCL-25 has demonstrated sound reliability in clinical refugee samples [35, 37, 38], having exhibited excellent test-retest reliability $(r=0.89)$ and internal consistency, which has been found to exceed 0.88 in refugee samples [37, 39].

\section{Harvard trauma questionnaire - Revised (HTQ-R)}

The Harvard Trauma Questionnaire (HTQ) [26] was designed to assess trauma related to mass violence and its sequelae, and has been used in numerous studies with forced migrant populations. It has been validated in several non-Western populations (e.g., Cambodian, Japanese, Vietnamese, Lao, Bosnian and Croatian) and met four of five criteria in a critical evaluation of instruments used to measure refugee trauma and health status [35].

The HTQ-R comprises four parts: Part 1: trauma events; Part 2: personal description; Part 3: head injury; Part 4: trauma symptoms. Only parts I and IV were included in the protocol, to assess previous traumatic events and PTSD symptoms, respectively, as both are established predictors of PTSD and are associated with other mental disorders, such as depression. Part IV comprises 40 items of trauma symptoms using a scale of 1 (not at all), 2 (a little), 3 (quite a bit), and 4 (extremely) indicating the degree of distress within the previous seven days. The first 16 items (PTSD subscale) were derived from the DSM-IV criteria for post-traumatic stress disorder [26]. The remaining 24 items constitute a 'refugee-specific' subscale which measure self-perceived level of functioning and social disability, and which may be more highly correlated with traumarelated distress than the symptoms of PTSD [26].

The HTQ has demonstrated excellent statistical properties, including high interrater reliability $(K=0.93)$, scale test-retest reliability ( 1 week, $r=0.89$ ); and internal scale consistency $(\alpha=0.90)$ for the traumatic events sale (Part I). The trauma symptoms scale (Part IV) has demonstrated high interrater reliability $(\mathrm{K}=0.98)$, scale test-retest reliability (1 week, $r=0.92$ ); and internal scale consistency $(\alpha=0.96)$. The PTSD items (Part IV, 1-16) have exhibited reasonable SN (0.78) and SP (0.65) as a screening instrument for PTSD, however, the additional 'refugee specific' items (Part IV) increased the SP to 0.78 (SN remained unchanged).

Both the HSCL-25 and HTQ are considered to be gold standard self-report measures of psychiatric symptomatology in forced migrant populations, having demonstrated robust psychometric properties [26, 35], and are among the most widely used self-report measures for psychological distress in forced migrants.

\section{Psychiatric epidemiology research interview-demoralisation scale (PERI-D)}

The PERI-D [28] demoralisation scale comprises 27 items which measure nonspecific distress using a five-point scale ranging from 0 ('never') to 4 ('very often') with a composite score calculated by dividing the total score by the number of items completed. It has been employed in a conflictaffected population [40], clinical [41] and community [42] populations, and with Jewish and Middle Eastern immigrants [43-46].

\section{Post-migration living difficulties checklist (PMLDC)}

The PMLDC [47] is a 23-item checklist to assess current life stressors of asylum-seekers, having been developed from an ad hoc checklist of a range of typical problems reported by asylum-seekers [48]. Hence, it is an important instrument to measure life experiences other than war [35]. Each item is rated on a 5-point scale from 'no problem' to 'very serious problem, with a composite score determined. The PMLDC has been used $[47,49,50]$ or adapted for use [51,52] in forced migrant populations internationally.

\section{Statistical analysis}

All data were analysed using $R$ version 3.2.2 [53]. The $e R m$ [54] and ltm [55] packages were used to conduct the Rasch modelling.

\section{Rasch analysis}

Rasch analysis was conducted to examine the construct validity of the STAR-MH at instrument, person, and 
item levels. Rasch modelling is a probabilistic approach to estimate the difficulty of questionnaire items, which assumes that a single latent construct accounts for item responses [56]. The probability of a person endorsing an item is a logistic function of the item difficulty and person ability [57]. This logistic function is an interval scale with a midpoint of 0 . The items are ordered on the scale in descending order according to their difficulty level. Items on the top of the scale are considered more difficult and have lower probabilities that a person endorses it, whereas items at the bottom of the scale are deemed less difficult and have a high probability of being endorsed [57]. In the present context, the latent variable is psychological distress and a high item score indicates higher levels of psychological distress. Therefore, the interpretation of item difficulty is such that a high item difficulty estimate relates to fewer people endorsing the symptom of psychological distress. Conversely, individuals achieving a lower score on the STAR-MH items experience lower psychological distress and are assigned a lower person ability.

\section{Dimensionality and local item dependence}

The Rasch model assumes that a set of items are unidimensional, with items being locally independent from each other. The procedure of Drasgow and Lissak [58] was used to check the dimensionality of the dichotomously scored STAR-MH responses using modified parallel analysis with 2000 Monte Carlo samples. The test is implemented in the ltm [55] package and a non-significant $p$-value is indicative of unidimensionality.

Local dependency detection was conducted by using Ponocny's "T1" test [59] for local dependence assessing increased inter-item correlations for all 21 possible item pair combinations. This test is implemented by the NPtest function in the $e R m$ package [54] and a statistically significant test at $p<.05$ is indicative of local dependence.

\section{Item fit}

The information-weighted fit (infit) and the outliersensitive fit (outfit) were used to test whether the items fit the expected model. The infit statistic is more sensitive to unexpected responses to items closest to the person's ability level, whereas outfit statistic is more sensitive to unexpected responses to items further away from the person's ability [60]. Items with respective infit and outfit values between 0.60 and 1.40 are considered a good fit to the Rasch model [61]. In addition, standardized infit (infit- $t$ ) and outfit (outfit- $t$ ) statistics and an associated chi-squared statistic were calculated. Items with standardized infit and outfit values of between -2.50 and 2.50 are deemed to indicate adequate fit to the model. To account for multiple testing using Bonferroni corrections, the chi-squared $p$-value was multiplied by the number of items in the Rasch model.
For this series of analyses, an adjusted $p$-value of less than 0.05 was considered statistically significant.

\section{Differential item functioning (DIF)}

DIF or item bias can occur when different groups within a sample, despite having the same levels of the latent trait (i.e., psychological distress), respond in a different manner to an individual item [57,62]. There should be no differences in the probability to endorse a certain item based on the subgroups. The logistic regression method [63] implemented by the difLogistic function in the difR package [64] was used to assess DIF for subgroups based on sex, age, interpreter use, support agency, country of origin, marital status, travel mode, and post-migration detention status. Age was dichotomised based on the median age (18-33 vs. $34+)$, while country of origin was dichotomised into Southern Asia or other. An effect size based on Nagelkerke's $R^{2}$ statistic [65] provides a quantification of DIF [66]. The effect sizes are classified as "negligible" $\left(R^{2}<0.035\right)$, "moderate" $\left(0.035 \leq R^{2} \leq 0.07\right)$, "large" $\left(R^{2}>0.07\right)$ [67]. Given the multiple comparisons for each item, the Benjamini and Hochberg (BH) false discovery rate was applied to control for Type I error. This is the recommended adjustment when assessing DIF using logistic regression [68].

\section{Internal consistency}

The Person Separation Index (PSI) provides an indication of the internal consistency of the scale and is interpreted in the same manner as the Cronbach alpha coefficient [62]. While a PSI of 0.70 is considered a minimal value for group or research use and 0.85 for individual or clinical use [69], it can be influenced by the number of items in the scale. For scales with few items, it is recommended to report the mean inter-item correlation, with an optimal range of between 0.20 and 0.40 [70].

\section{Receive operating characteristic (ROC) analyses}

A receiver operating characteristics (ROC) plot was used to assess the sensitivity and specificity of the STAR-MH in discriminating between participants with caseness for PTSD/MDD and those without. Sensitivity is the proportion of true positives that is correctly identified by the test, while specificity is the proportion of true negatives that is correctly identified by the test [71]. A ROC plot is obtained by calculating the sensitivity and specificity of every observed data value and plotting sensitivity against 1 - specificity. The area under the ROC curve (AUC) is the most used measure of the accuracy of a diagnostic test and ranges between 0.5 and 1 , with 0.5 indicating poor accuracy and 1 representing perfect accuracy. Furthermore, a ROC analysis is independent of disease prevalence [71]. 
The bootstrapped optimism-corrected AUC was calculated to estimate the deterioration that the model will have when applied to new participants using the algorithm of Harrell et al. [72]. This approach outperforms split-sample validation, particularly when the sample size is limited [72, 73]. If the bootstrap optimism-corrected AUC shows acceptable predictive accuracy, then the model is validated [72]. As recommended by Harrell et al. [72], 200 resamples with replacement were drawn from the original data $(N=185)$.

Youden's $J$ statistic [74] was used to determine the optimal cut-off score for the STAR-MH. This was calculated as the sum of sensitivity and specificity for each cut-off value to indicate the test score at which the greatest proportion of individuals is correctly identified as being cases and non-cases. The positive and negative likelihood ratios (PLR/NLR), positive and negative predictive values (PPV/NPV), and predictive accuracy were also calculated for each cut-off score. The $R$ package pROC [75] was used to conduct the ROC analyses.

\section{Results}

The final pilot ('validation sample') screened and psychiatrically evaluated 192 participants from 36 countries and 27 different language groups. Eighty-seven participants were recruited through the ASRC, whilst 85 declined, and 105 individuals were recruited through the $\mathrm{MHC}$ whilst 10 declined. Overall, this represents a participation rate of $66.9 \%$.

The STAR-MH was deemed to be culturally appropriate by community leaders of the three largest language groups represented in the sample (i.e., Farsi, Dari and Tamil, comprising 43\% of the sample). All confirmed the cultural validity of the tool and believed the tool would be a useful resource in their respective communities.

Participants ranged from 19 to 82 years, with a median age of 33 years (IQR 36-43), and median time in Australia of 2 years (IQR 0.70-3.11). Demographic and clinical characteristics of the sample $(N=192)$ are presented in Additional file 1: Table S1.

Twenty-eight non-mental health workers administered the screening tool, with a median administration time of six minutes $(I Q R=5-7)$, irrespective of whether an interpreter was used (i.e., $M d=5, I Q R=4-7$ without interpreter; $M d=6, I Q R=5-7$ with interpreter). The M.I.N.I validation interview took place a median of 5.50 (IQR 09) days post-screen and identified rates of MDD and PTSD at $29.7 \%$ and $19.9 \%$ respectively, with the prevalence of PTSD and/or MDD being 32.3\%. Sixty-four participants (33.3\%) met criteria for at least one mental disorder and there were only two cases (both of whom were diagnosed with substance use disorder [SUD]; one was nil current) that were not comorbid with PTSD or MDD. Hence for $99 \%$ of the total sample, other diagnosed mental disorders (i.e., GAD 3\%; panic disorder 2\%; SUD $1.5 \%$; psychosis $1 \%$; OCD $0.5 \%$; agoraphobia $0.5 \%$ ) were comorbid with PTSD or MDD. Suicidality was $6.8 \%$.

\section{Preliminary analyses}

Cases with missing responses $(N=7,3.6 \%)$ to the STAR$\mathrm{MH}$ were omitted from further analyses. Thus, the resulting sample size was 185 participants (Table 2). Table 3 presents the response frequencies for the eight items which comprised the prospectively tested scale (see Validation Sample), excluding the two immediate screen-in items. Item 9 had two missing values and item 10 had five. The response frequencies for the eight items for the total sample $(N=192)$ can be found in Additional file 2: Table S2.

The plot of the total score versus the proportion of endorsed responses for each item (see Fig. 2) revealed low variance for item 6 (sleep), demonstrating a 30\% chance that individuals would endorse this item even if they did not endorse other items. Furthermore, the probability of endorsing the sleep item increased as respondents endorsed other items (i.e., higher total score). Based on these findings of unacceptably low specificity item 6 was dropped from subsequent analyses.

\section{Rasch analysis \\ Item fit}

Table 4 presents the item fit statistics from the Rasch analysis. All items had an infit statistic between 0.91 and 1.20 , and an outfit statistic between 0.85 and 1.27. Similarly, the outfit- $t$ statistic ranged from -1.09 to 1.97 , and the infit- $t$ statistic ranged from 0.89 to 1.20 . The chisquared test for each item was not statistically significant. This pattern of results indicated that none of the items were misfitting.

\section{Dimensionality and local dependence}

The unidimensionality test was not statistically significant $(p=0.785)$, suggesting that the STAR-MH was unidimensional. Ponocny's "T1" test indicated that there were no locally dependent items (all $p$-values $>0.05$ ).

\section{Differential item functioning (DIF)}

The analyses indicated that there was a moderate effect of DIF $\left(R^{2}=0.04, p=0.023\right.$ ) for item 4 (Have you felt very fearful?) caused by support agency. The ARC group were less likely to endorse this item. No other instances of DIF were detected for sex, age, interpreter use, country of origin, marital status, travel mode, and post-migration detention status.

\section{Internal consistency}

The PSI for the 7-item STAR-MH scale was 0.75, which indicated good usability at the group levels, but a lack of sensitivity for individual analyses. However, the average 
Table 2 Demographic and clinical variables of participants $(N=185)$

\begin{tabular}{ll}
\hline & $N^{\mathrm{a}}(\%)^{\mathrm{b}}$ \\
\hline Mender & $129(69.7)$ \\
Age group & \\
$18-24$ & $24(13.0)$ \\
$25-34$ & $75(40.5)$ \\
$35-44$ & $48(25.9)$ \\
$45-54$ & $27(14.6)$ \\
$55+$ & $11(5.9)$ \\
Marital status & \\
Partnered & $111(60.0)$
\end{tabular}

Partnered

Mode of Arrival

Irregular maritime arrival

Continent of Origin (UN geoscheme)

Africa

East Africa

North Africa

$10(5.4)$

West Africa

Asia

South Asia

South-East Asia

West Asia

Other

Interpreter required

Yes (screening)

Yes (interview)

Pre-migration camp/detention

Yes

Post-migration Immigration Detention

Yes

Years in Australia

$<1$ year

$1-2$ years

2-3 years

$>3$ years

Residency status

Temporary Visa (Asylum-seeker)

Permanent Residency (Refugee)

Mental health diagnosis (Australia)

Yes

MINI-assessed Post-traumatic stress disorder (PTSD)

Yes
Table 2 Demographic and clinical variables of participants $(N=185)$ (Continued)

\begin{tabular}{|c|c|}
\hline & $N^{a}(\%)^{b}$ \\
\hline \multicolumn{2}{|c|}{ MINI-assessed Major depressive disorder (MDD) } \\
\hline Yes & $56(30.3 .7)$ \\
\hline \multicolumn{2}{|c|}{ Either PTSD or MDD (MINI) } \\
\hline Yes & $61(33.0)$ \\
\hline \multicolumn{2}{|c|}{$\begin{array}{l}\text { a Total } n \text { s may be less than } 185 \text { due to missing data } \\
{ }^{b} \text { Refers to valid percentage, excluding missing data } \\
{ }_{n} n=184\end{array}$} \\
\hline
\end{tabular}

\section{ROC analyses}

Figure 3 presents the ROC plot for participants with caseness for PTSD/MDD compared to those without. The AUC for this analysis was 0.912 (95\% CI $=0.868-$ 0.956). Using bootstrap validation, the optimism-corrected AUC was 0.911 , which represents the predictive ability of the model in future forced migrants.

Table 5 shows that a STAR-MH cut-off score of 3 produced the best balance of sensitivity and specificity based on Youden's J. While a cut-off score of $\geq 2$ for the 7 -item scale gave a lower positive predictive value than a score of $\geq 3$, it provided higher negative predictive value, which was a desirable requisite for the screening tool. A cut-off score of three rather than two resulted in a greater PLR, with moderate utility $(\sim+20-30 \%$ change in probability) whilst the NLR was in the moderate to high range $(\sim-30-45 \%$ change in probability) for both cut points [76]. Similarly, the overall diagnostic accuracy was above $80 \%$ for both.

\section{Discussion}

This paper presents the psychometric properties and utility of a screening tool for use by non-mental health practitioners to screen for mental disorders in asylumseekers and new refugees (ASR). Our aim was to develop a brief, highly sensitive and easily administrable tool which would alert non-mental health workers of the need to refer a positively screened individual for a mental health evaluation.

The resultant STAR-MH is a psychometrically robust 9item screening tool comprising two 'immediate screen-in' 187 (97.3) items and a 7-item scale with a cut-off score of $\geq 2$. The ad5 (2.7) ministration time was six minutes, with or without an interpreter, whilst noting in routine use that a positive response to either immediate screen-in item (Items 1 or 2) would obviate the need to continue the screen. Therefore, based on our findings, those who screened positive $(22.7 \% ; n=$ 42) to one of the first two items would have been effectively screened in less than $3 \mathrm{~min}$.

Given the small number of items comprising the STAR-MH, internal consistency was sound, and the 
Table 3 Response frequencies for STAR-MH items

\begin{tabular}{llll}
\hline & Item & Yes & No \\
$n(\%)^{\mathrm{a}}$ & \\
\hline 3. & Have you felt very restless, like you can't keep still? & $55(29.7 \%)$ & $130(70.3 \%)$ \\
4. & Have you lost interest in things? & $55(29.7 \%)$ & $130(70.3 \%)$ \\
5. & Have you worried about going crazy or 'losing your mind'? & $48(25.9 \%)$ & $137(74.1 \%)$ \\
6. & Have you had a lot of trouble sleeping? & $62(33.5 \%)$ & $122(66.5)$ \\
7. & Have you felt very fearful? & $62(33.5 \%)$ & $123(66.5 \%)$ \\
8. & Have you felt very trapped or caught? & $59(31.9 \%)$ & $126(68.1 \%)$ \\
9. & Have you had a lot of pain in your body? & $61(33.0 \%)$ & $124(67.0 \%)$ \\
10. & Have you felt very worthless? & $54(29.2 \%)$ & $131(70.8 \%)$ \\
\hline
\end{tabular}

Note. ${ }^{\mathrm{a}}$ Percentages based on $N=185$

Rasch analyses confirmed the unidimensionality of the 7-item scale and goodness-of-fit of all items. It performed well in the latent construct of psychological distress according to the differential item functioning (DIF) across all subgroups apart from one pilot site for item 7 (Have you felt very fearful?). A possible explanation may lie in differing ecological influences between the ASRC and MHC that were not accounted for by the pilot. Further post hoc analyses would need to be conducted to elucidate this, particularly the relationship between fear and psychological distress for this population. However, a putative explanation may lie in the high degree of psychosocial support received by ASRC participants. The protective role of social-emotional support in the mental health of forced migrant populations has been well-established [14, 77].

The ROC curve indicated the STAR-MH to be performing in the excellent range, with a diagnostic accuracy of between 81 and $84 \%$, depending on the cut-off score. The empirically derived cut point suggested an optimum cutoff score of $\geq 3$, however privileging sensitivity to minimise screening out 'true' cases of PTSD or MDD indicated a cut-off score of $\geq 2$. It is anticipated that field testing in a larger ASR sample population will clarify the optimal cutoff score, however, $\geq 2$ is most consistent with the aim of optimising sensitivity. In depth testing within specific language and ethnic groups would be justified to confirm the validity of these findings. However, the findings from the bootstrap validation analyses suggest that the diagnostic accuracy of the STAR-MH will not likely be diminished when used with other forced migrant populations.

Notwithstanding the inadequacies of the Western diagnostic lens, PTSD is the most 'robust' epidemiological diagnostic construct that we have for assessing and treating trauma-related symptomatology. However, it is important

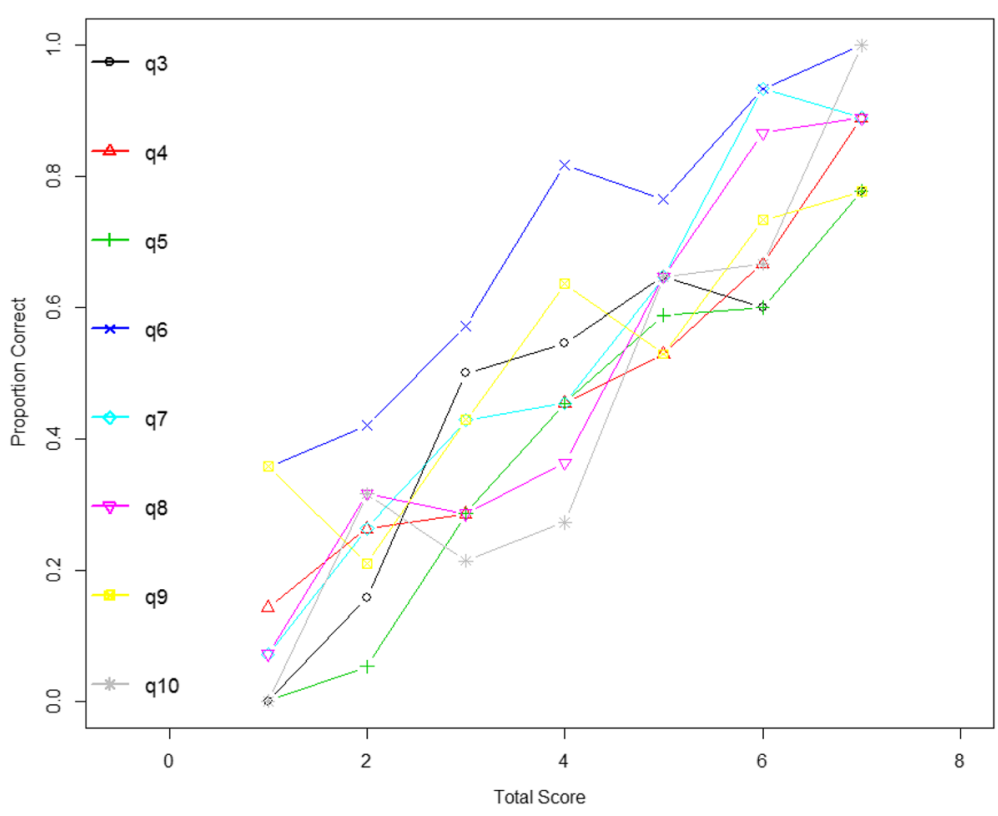

Fig. 2 Total score versus proportion of endorsed (correct) responses for items 3-10 
Table 4 STAR-MH item difficulty estimates, chi-squared test, outfit, and infit statistics, and standardised outfit and infit statistics

\begin{tabular}{|c|c|c|c|c|c|c|c|c|c|}
\hline Item & Difficulty & SE & $x^{2}$ & $d f$ & $p$ & Outfit & Infit & Outfit- $t$ & Infit- $t$ \\
\hline Have you felt very restless, like you can't keep still? & 0.06 & 0.20 & 98.6 & 94 & 1 & 1.05 & 1.06 & 0.41 & 1.06 \\
\hline Have you lost interest in things? & 0.06 & 0.20 & 99.4 & 94 & 0.269 & 1.06 & 1.02 & 0.47 & 1.02 \\
\hline Have you worried about going crazy or 'losing your mind'? & 0.40 & 0.21 & 80.2 & 94 & 1 & 0.85 & 0.95 & -0.99 & 0.95 \\
\hline Have you felt very fearful? & -0.27 & 0.20 & 81.8 & 94 & 1 & 0.87 & 0.91 & -0.99 & 0.91 \\
\hline Have you felt very trapped or caught? & -0.13 & 0.20 & 90.5 & 94 & 1 & 0.96 & 0.97 & -0.24 & 0.97 \\
\hline Have you had a lot of pain in your body? & -0.22 & 0.20 & 119.6 & 94 & 1 & 1.27 & 1.20 & 1.97 & 1.20 \\
\hline Have you felt very worthless? & 0.11 & 0.20 & 80.5 & 94 & 1 & 0.86 & 0.89 & -1.09 & 0.89 \\
\hline
\end{tabular}

to note that diagnostic criteria for disorders such as PTSD and depression are limited in their ability to predict distress and impairment across diverse linguistic and cultural groups. Hence, the items resulting in the final version of the STAR-MH were derived inductively, exploiting measures from scales that have been adapted for use in a range of cultural groups to maximise cultural sensitivity. It is therefore reasoned that the items comprising the STAR$\mathrm{MH}$ reflect trauma manifestations of forced migrant populations rather than corresponding directly to the Western construct of symptoms.

Study limitations included the relatively small sample, consistent with sampling difficulties characteristic of asylum-seeker populations in general [78]. Despite this, the prevalence of PTSD and/or MDD found in this population $(32 \%)$ was consistent with rates of these disorders found in other ASR populations internationally [10]. Nonetheless, field testing will need to be undertaken to confirm the validity and reliability of the STAR-MH in larger ASR sample populations. Whilst we endeavoured to recruit both a representative and heterogeneous group of administrators and ASR participants (i.e., culturally and linguistically diverse sample), until field studies have been undertaken, the external validity of the tool must be interpreted with caution.

Although administrators were instructed to read the STAR-MH items faithfully and neutrally, no systematic administrator observation was undertaken. In situ translation with different interpreters also presents an increased risk to the fidelity of administration. This raises the critical

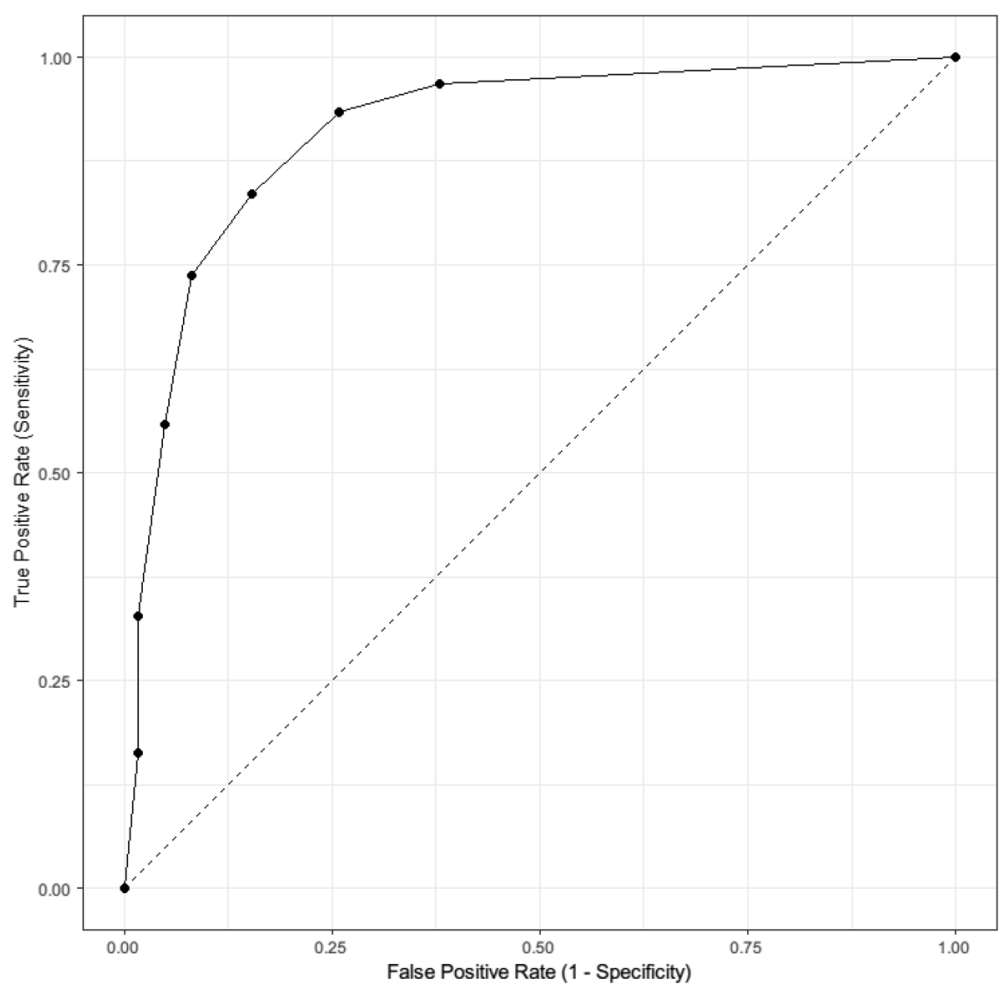

Fig. 3 Receiver operating characteristic plot of STAR-MH scores of participants with caseness for PTSD/MDD and those without 


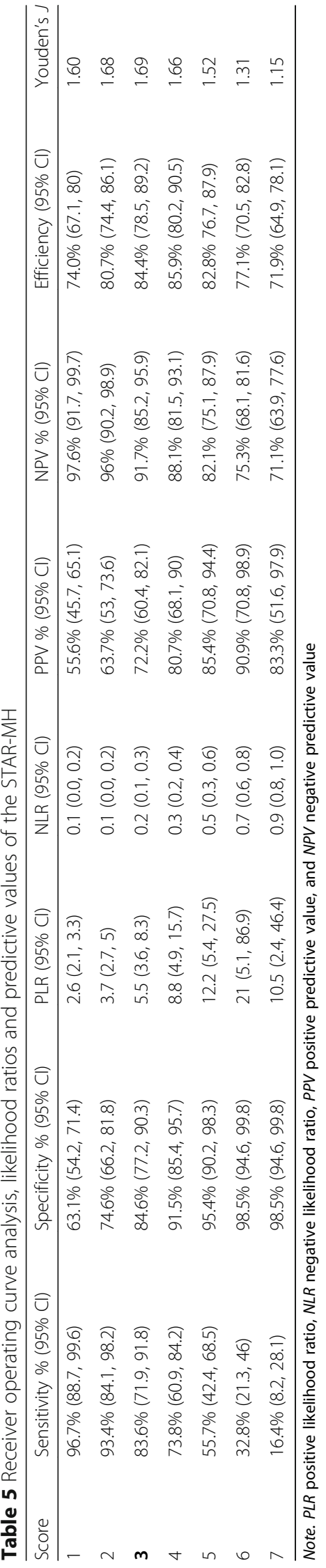


issue of how items were verbally translated by interpreters into culturally valid idioms. However, the STAR-MH is an amalgam of items from gold standard measures of PTSD and MDD symptomatology in ASR populations [35, 79]. Furthermore, leaders from several ethnic communities were consulted about the cultural sensitivity and utility of the STAR-MH and endorsed it for use in their respective communities.

Whilst the brevity and simplicity of the tool means that administrator training is not necessary (i.e., the worker need only follow the instructions on the form itself), the STAR-MH is not designed for self-administration or for lay administration but rather for a worker in the field. This is to ensure that a referral processes can be instigated in the event of a positive screen result and/or an abreaction during the screening process, although none of the latter were noted in this study.

The STAR-MH differentiates itself from related tools in its screening breadth and predictive validity. Hence, in comparison to other widely used screening tools (e.g., K10 and PTSD-8), the STAR-MH screens for both PTSD and MDD. The high comorbidity of PTSD and depression in forced migrant populations [80-82], necessitates a tool that can efficiently screen for both disorders. Unlike the K10 and RHS-15, the STAR-MH has clinical predictive validity, having been validated against a diagnostic instrument in both primary health and community settings. In contrast, relatively high rates of misclassified true cases and non-cases in studies that utilised the K10 in culturally diverse populations have raised questions about its suitability for non-Western groups [17].

\section{Conclusion}

The STAR-MH is a simple, sensitive screening tool to facilitate mental health referrals for asylum-seekers and new refugees at the agency of first presentation. The pilot of a 9item version has demonstrated promising results ahead of field testing to ascertain its external validity in communitydwelling asylum-seeker and new refugee populations in industrialised host nations.

\section{Additional files}

Additional file 1: Table S1. Demographic and clinical variables of participants $(N=192)$. Demographic and clinical variables of participants for the total sample, including cases with missing variables. (PDF $152 \mathrm{~kb}$ )

Additional file 2: Table S2. Response frequencies for STAR-MH items $(N=192)$. Response frequencies for STAR-MH items 3-10 for total sample, including cases with missing variables. (PDF $243 \mathrm{~kb}$ )

\section{Abbreviations}

ASR: Asylum seekers and refugees asylum-seekers; ASRC: Asylum Seeker Resource Centre; AUC: Area under the curve; Cl: Confidence intervals; DIF: Differential Item Functioning; GP: General Practitioner; HSCL-25: Hopkins Symptom Checklist-25; HTQ: Harvard Trauma Questionnaire; M.I.N.I.: Mini International Neuropsychiatric Interview; MDD: Major depressive disorder;
MHC: Monash Community Health; NLR: Negative likelihood ratio; NPV: Negative predictive value; PERI-D: Psychiatric Epidemiology Research InterviewDemoralisation Scale; PLR: Positive likelihood ratio; PMLDC: Post-migration Living Difficulties Checklist; PPV: Positive predictive value; PSI: The Person Separation Index; PTSD: Post-traumatic stress disorder; ROC: Receiver operating characteristic; SN: Sensitivity; SP: Specificity; STAR-MH: Screening tool for asylum seeker and refugee mental health; WHO: World Health Organisation

\section{Acknowledgements}

The authors would like to acknowledge the patients and staff at the Monash Health Refugee Health and Dental services, and the members, staff and volunteers at the Asylum Seeker Resource Centre for theirassistance throughout the pilot and validation studies.

\section{Funding}

This project was funded by Cabrini Health and supported by the B.B \& A Miller Fund.

Funding bodies had no role in the study design, collection and analysis of data, or writing of the manuscript.

\section{Availability of data and materials}

The datasets used and/or analysed during the current study are available from the corresponding author on reasonable request.

\section{Authors' contributions}

$\mathrm{DH}$ and SS conceived and designed this study. DH and SS secured funding for the study. DH conducted the study. DH and SM undertook the statistical analysis. All authors drafted, read and approved the final manuscript.

\section{Ethics approval and consent to participate}

The research was approved by the Human Research Ethics Committees of Monash Health and the University of Melbourne, Victoria, Australia, and conforms with the provisions of the Declaration of Helsinki in 1995 (5th revision). All participants provided written consent prior to being screened.

\section{Consent for publication}

Not applicable

\section{Competing interests}

The authors declare that they have no competing interests.

\section{Publisher's Note}

Springer Nature remains neutral with regard to jurisdictional claims in published maps and institutional affiliations.

\section{Author details}

${ }^{1}$ Cabrini Institute, 154 Wattletree Road, Malvern, VIC 3144, Australia. ${ }^{2}$ Florey Institute of Neuroscience and Mental Health, 30 Royal Parade (Cnr Genetics Lane), Parkville, VIC 3052, Australia. ${ }^{3}$ Department of Psychiatry, Faculty of Medicine, Dentistry and Health Sciences, University of Melbourne, Parkville, VIC 3010, Australia. ${ }^{4}$ Department of Psychiatry, School of Clinical Sciences, Monash University, Clayton, VIC 3168, Australia. ${ }^{5}$ Adult Psychiatry, Monash Medical Centre, Clayton, VIC 3168, Australia.

Received: 12 January 2018 Accepted: 12 March 2018

Published online: 16 March 2018

\section{References}

1. UNHCR: Global Trends: the world at war. In.; 2014.

2. Heeren M, Mueller J, Ehlert U, Schnyder U, Copiery N, Maier T. Mental health of asylum seekers: a cross-sectional study of psychiatric disorders. BMC Psychiatry. 2012;12:114-21.

3. Hollifield M, Verbillis-Kolp S, Farmer B, Toolson EC, Woldehaimanot T, Yamazaki J, Holland A, St. Clair J, SooHoo J. The refugee health Screener-15 (RHS-15): development and validation of an instrument for anxiety, depression, and PTSD in refugees. Gen Hosp Psychiatry. 2013;35(2):202-9.

4. Shannon PJ, Im H, Becher E, Simmelink J, Wieling E, O'Fallon A. Screening for War Trauma, Torture, and Mental Health Symptoms Among Newly Arrived Refugees: A National Survey of U.S. Refugee Health Coordinators. Journal of Immigrant \& Refugee Studies. 2012;10(4):380-94. 
5. Shannon PJ, Vinson GA, Wieling E, Cook T, Letts J. Torture, war trauma, and mental health symptoms of newly arrived Karen refugees. Journal of Loss and Trauma. 2015;20(6):1-14.

6. Hvass AMF, Wejse C. Systematic health screening of refugees after resettlement in recipient countries: a scoping review. Ann Hum Biol. 2017; 44:1-9.

7. Barnes DM. Mental health screening in a refugee population: a program report. J Immigr Health. 2001;3(3):141-9.

8. McMahon J, MacFarlane A, Avalos G, Cantillon P, Murphy AW. A survey of asylum seekers' general practice service utilisation and morbidity patterns. Ir Med J. 2007;100(5):461-4

9. Porter M, Haslam N. Predisplacement and postdisplacement factors associated with mental health of refugees and internally displaced persons. JAMA. 2005;294(5):602-12.

10. Steel Z, Chey T, Silove DM, Marnane C, Bryant RA, van Ommeren MH. Association of torture and other potentially traumatic events with mental health outcomes among populations exposed to mass conflict and displacement: a systematic review and meta-analysis. JAMA. 2009;302(5):537-49.

11. Gerritsen AA, Bramsen I, Devillé W, van Willigen LH, Hovens JE, van der Ploeg HM. Physical and mental health of afghan, Iranian and Somali asylum seekers and refugees living in the Netherlands. Soc Psychiatry Psychiatr Epidemiol. 2006;41(1):18-26.

12. Toar M, O'Brien KK, Fahey T. Comparison of self-reported health \& healthcare utilization between asylum seekers and refugees: An observational study. BMC Public Health. 2009;9:214-24.

13. Heeren M, Wittmann L, Ehlert U, Schnyder U, Maier T, Müller J. Psychopathology and resident status-comparing asylum seekers, refugees, illegal migrants, labor migrants, and residents. Compr Psychiatry. 2014;55(4):818-25.

14. Hocking DC, Kennedy GA, Sundram S. Social factors ameliorate psychiatric disorders in community-based asylum seekers independent of visa status. Psychiatry Res. 2015;230(2):628-36.

15. World Health Organization. Mental health action plan 2013-2020. In: Geneva: world health organisation; 2013.

16. Laban CJ, Gernaat H, Komproe IH, De Jong JTVM. Prevalence and predictors of health service use among Iraqi asylum seekers in the Netherlands. Soc Psychiatry Psychiatr Epidemiol. 2007:42(10):837-44.

17. Stolk Y, Kaplan I, Szwarc J. Clinical use of the Kessler psychological distress scales with culturally diverse groups. Int J Methods Psychiatr Res. 2014;23(2): 161-83.

18. Dowling A, Enticott J, Russell G. Measuring self-rated health status among resettled adult refugee populations to inform practice and policy - a scoping review. BMC Health Serv Res. 2017;17(1):817.

19. Beusenberg M, Orley JH, Organization WH: A User's guide to the self reporting questionnaire (SRQ-20). 1994.

20. Hansen M, Andersen TE, Armour C, Elklit A, Palic S, Mackrill T. PTSD-8: short PTSD inventory. Clin Pract Epidemiol Ment Health. 2010;6:101-8.

21. Kroenke K, Spitzer RL, Williams JB. The PHQ-9: validity of a brief depression severity measure. J Gen Intern Med. 2001;16(9):600-13.

22. Liebschutz J, Saitz R, Brower V, Keane T, Lloyd-Travaglini C, Averbuch T, Samet J. PTSD in Urban Primary Care: high prevalence and low physician recognition. J Gen Intern Med. 2007;22(6):719-26.

23. Ehlers A, Gene-Cos N, Perrin S. Low recognition of post-traumatic stress disorder in primary care. London Journal of Primary Care. 2009;2(1):36-42.

24. Rodriguez BF, Weisberg RB, Pagano ME, Machan JT, Culpepper L, Keller MB. Mental health treatment received by primary care patients with posttraumatic stress disorder. The Journal of Clinical Psychiatry. 2003;64(10):1230-6.

25. Hocking DC, Sundram S. Screening tool for asylum-seeker mental health (STAMH): a pilot study. Eur Psychiatry. 2016;33:S231.

26. Mollica RF, LS MD, Massagli MP, Silove DM. Measuring Trauma, Measuring Torture: Instructions and guidance on the utilization of the Harvard Program in Refugee Trauma's versions of the Hopkins Symptom Checklist-25 (HSCL25) \& the Harvard Trauma Questionnaire (HTQ). Cambridge, MA: Harvard Program in Refugee Trauma; 2004.

27. Momartin S, Steel Z, Coello M, Aroche JR, Silove D, Brooks R. A comparison of the mental health of refugees with temporary versus permanent protection visas. In: Med J Aust, vol. 185; 2006. p. 357-61.

28. Dohrenwend BP, Shrout PE, Egri G, Mendelsohn FS. Nonspecific psychological distress and other dimensions of psychopathology: measures for use in the general population. Arch Gen Psychiatry. 1980;37(11):1229-36.

29. Sheehan DV, Lecrubier $Y$, Sheehan $\mathrm{KH}$, Amorim $\mathrm{P}$, Janavs J, Weiller $\mathrm{E}$ Hergueta T, Baker R, Dunbar GC. The mini-international neuropsychiatric interview (M.I.N.I.): the development and validation of a structured diagnostic psychiatric interview for DSM-IV and ICD-10. J Clin Psychiatry. 1998;59(Suppl 20):22-33.

30. Sheehan $D$, Lecrubier $Y$, Sheehan $K H$, Janavs J, Weiller E, Keskiner A, Schinka J, Knapp E, Sheehan M, Dunbar G. The validity of the MINI international neuropsychiatric interview (MINI) according to the SCID-P and its reliability. Eur Psychiatry. 1997;12(5):232-41.

31. Lecrubier Y, Sheehan DV, Weiller E, Amorim P, Bonora I, Harnett Sheehan K, Janavs J, Dunbar GC. The MINI international neuropsychiatric interview (MINI). A short diagnostic structured interview: reliability and validity according to the CIDI. Eur Psychiatry. 1997;12(5):224-31.

32. Bogic M, Njoku A, Priebe S. Long-term mental health of war-refugees: a systematic literature review. BMC Int Health Hum Rights. 2015;15(1):29.

33. Jankovic J, Bremner S, Bogic M, Lecic-Tosevski D, Ajdukovic D, Franciskovic T, Galeazzi GM, Kucukalic A, Morina N, Popovski M, et al. Trauma and suicidality in war affected communities. Eur Psychiatry. 2013;28(8):514-20.

34. Priebe S, Bogic M, Ajdukovic D, Franciskovic T, Galeazzi GM, Kucukalic A, Schutzwohl M. Mental disorders following war in the Balkans: a study in 5 countries. JAMA Psychiatry. 2010;67(5):518-28.

35. Hollifield M, Warner TD, Lian N, Krakow B, Jenkins JH, Kesler J, Stevenson J, Westermeyer J. Measuring trauma and health status in refugees: a critical review. JAMA. 2002;288(5):611-21.

36. Mollica RF, Wyshak G, de Marneffe D, Khuon F, Lavelle J. Indochinese versions of the Hopkins symptom Checklist-25: a screening instrument for the psychiatric care of refugees. Am J Psychiatry. 1987;144(4):497-500.

37. Lhewa D, Banu S, Rosenfeld B, Keller A. Validation of a Tibetan translation of the Hopkins symptom checklist-25 and the Harvard trauma questionnaire. Assessment. 2007:14(3):223-30.

38. Khuon F, Lavelle J. Indochinese versions of the Hopkins symptom Checklist25: a screening instrument for the psychiatric care of refugees. Am J Psychiatry. 1987;144(4):497-500.

39. Tinghög P, Carstensen J. Cross-cultural equivalence of HSCL-25 and WHO (ten) wellbeing index: findings from a population-based survey of immigrants and non-immigrants in Sweden. Community Ment Health J. 2010;46(1):65-76.

40. Levav I, Kohn R, Billig M. The protective factor of religiosity under terrorism. Psychiatry: Interpersonal and Biological Processes. 2008;71(1):46-58.

41. Shrout PE, Dohrenwend BP, Levav I. A discriminant rule for screening cases of diverse diagnostic types: preliminary results. J Consult Clin Psychol. 1986;54(3):314-9.

42. Gilboa S, Levav I, Gilboa L, Ruiz F. The epidemiology of demoralization in a kibbutz. Acta Psychiatr Scand. 1990;82(1):60-4.

43. Ritsner M, Rabinowitz J, Slyuzberg M. The Talbieh brief distress inventory: a brief instrument to measure psychological distress among immigrants. Compr Psychiatry. 1995;36(6):448-53.

44. Ritsner M, Ponizovsky A, Chemelevsky M, Zetser F, Durst R, Ginath Y. Effects of immigration on the mentally III-does it produce psychological distress? Compr Psychiatry. 1996;37(1):17-22

45. Dohrenwend BP, Levav I, Shrout PE. Screening scales from the psychiatric epidemiology research interview (PERI). In: Weissman A, Myers JK, Ross CE, editors. Community Surveys of Psychiatric Disorders. New Jersey: Rutgers University Press; 1986.

46. Lerner $Y$, Kertes J, Zilber N. Immigrants from the former soviet union, 5 years post-immigration to Israel: adaptation and risk factors for psychological distress. Psychol Med. 2005:35(12):1805.

47. Silove DM, Steel Z, McGorry P, Mohan P. Trauma exposure, postmigration stressors, and symptoms of anxiety, depression and post-traumatic stress in Tamil asylum-seekers: comparison with refugees and immigrants. Acta Psychiatr Scand. 1998;97(3):175-81.

48. Silove DM, Sinnerbrink I, Field A, Manicavasagar VL, Steel Z. Anxiety, depression and PTSD in asylum-seekers: associations with pre-migration trauma and post-migration stressors. Br J Psychiatry. 1997;170:351-7.

49. Schweitzer RD, Melville F, Steel Z, Lacherez P. Trauma, post-migration living difficulties, and social support as predictors of psychological adjustment in resettled Sudanese refugees. Aust N Z J Psychiatry. 2006;40(2):179-88.

50. Steel Z, Silove D, Brooks R, Momartin S, Alzuhairi B, Susljik I. Impact of immigration detention and temporary protection on the mental health of refugees. Br J Psychiatry. 2006:188:58-64.

51. Laban CJ, Gernaat H, Komproe IH, van der Tweel, I.,, De Jong JTVM: Postmigration living problems and common psychiatric disorders in Iraqi asylum seekers in the Netherlands. J Nerv Ment Dis 2005, 193(12):825-832. 
52. Ryan DA, Benson C, Dooley B. Psychological distress and the asylum process: a longitudinal study of forced migrants in Ireland. J Nerv Ment Dis. 2008;196(1):37-45.

53. R Core Team: R: A language and environment for statistical computing. Version 3.2.2. Vienna, Austria: R Foundation for Statistical Computing; 2015.

54. Mair P, Hatzinger R. Extended Rasch modeling: the eRm package for the application of IRT models in R. J Stat Softw. 2007:20(9):1-20.

55. Rizopoulos D: Itm: An R package for latent variable modeling and item response theory analyses.

56. Rasch G. An item analysis which takes individual differences into account. The British journal of mathematical and statistical psychology. 1966;19(1):49-57.

57. Bond TG, Fox CM. Applying the Rasch model: fundamental measurement in the human sciences, vol. 2. New Jersey: Lawrence Erlbaum Associates; 2007.

58. Drasgow F, Lissak RI. Modified parallel analysis: a procedure for examining the latent dimensionality of dichotomously scored item responses. J Appl Psychol. 1983;68(3):363-73.

59. Ponocny I. Nonparametric goodness-of-fit tests for the rasch model. Psychometrika. 2001;66(3):437-59.

60. Linacre JM. What do infit and outfit, mean-square and standardized mean. Rasch Measurement Transactions. 2002;16(2):878.

61. Wright $B D$, Linacre JM, Gustafson J, Martin-Lof P. Reasonable mean-square fit values. Rasch measurement Transactions. 1994:8(3):370.

62. Wright BD, Stone MH. Measurement essentials. 2nd ed. Wide Range Inc: Wilmington; 1999.

63. Swaminathan $\mathrm{H}$, Rogers $\mathrm{HJ}$. Detecting differential item functioning using logistic regression procedures. J Educ Meas. 1990;27(4):361-70.

64. Magis D, Béland S, Tuerlinckx F, De Boeck P. A general framework and an R package for the detection of dichotomous differential item functioning. Behav Res Methods. 2010;42(3):847-62.

65. Nagelkerke NJ. A note on a general definition of the coefficient of determination. Biometrika. 1991;78(3):691-2.

66. Gómez-Benito J, Hidalgo MD, Padilla J-L. Efficacy of effect size measures in logistic regression: an application for detecting DIF. Methodology. 2009;5(1):18-25.

67. Jodoin MG, Gierl MJ. Evaluating type I error and power rates using an effect size measure with the logistic regression procedure for DIF detection. Appl Meas Educ. 2001;14(4):329-49.

68. Kim J, Oshima TC. Effect of multiple testing adjustment in differential item functioning detection. Educ Psychol Meas. 2013;73(3):458-70.

69. Tennant A, Conaghan PG. The Rasch measurement model in rheumatology: what is it and why use it? When should it be applied, and what should one look for in a Rasch paper. Arthritis Care \& Research. 2007;57(8):1358-62.

70. Briggs SR, Cheek JM. The role of factor analysis in the development and evaluation of personality scales. J Pers. 1986;54(1):106-48.

71. Zhou XH, Obuchowski NA, DK MC. Statistical methods in diagnostic medicine. New York: Wiley-Interscience; 2002.

72. Harrell FE, Lee KL, Mark DB. Multivariable prognostic models: issues in developing models,evaluating assumptions and adequacy, and measuring and reducing errors. Stat Med. 1996;15(4):361-87.

73. Smith GCS, Seaman SR, Wood AM, Royston P, White IR. Correcting for optimistic prediction in small data sets. Am J Epidemiol. 2014;180(3):318-24.

74. Youden WJ. Index for rating diagnostic tests. Cancer. 1950;3(1):32-5.

75. Robin X, Turck N, Hainard A, Tiberti N, Lisacek F, Sanchez J-C, Müller M. PROC: an open-source package for R and $\mathrm{S}+$ to analyze and compare ROC curves. BMC Bioinformatics. 2011;12(1):1-8.

76. McGee S. Simplifying likelihood ratios. J Gen Intern Med. 2002;17(8):647-50

77. Silove DM, Steel Z. Understanding community psychosocial needs after disasters: implications for mental health services. In: J Postgrad Med, vol. 52; 2006. p. 121-5.

78. Silove DM, Steel Z, Watters C. Policies of deterrence and the mental health of asylum seekers. JAMA. 2000;284(5):604-11.

79. Kleijn W, Hovens J, Rodenburg J. Posttraumatic stress symptoms in refugees: assessments with the Harvard trauma questionnaire and the Hopkins symptom checklist-25 in different languages. Psychol Rep. 2001;88(2):527-32.

80. Nickerson A, Schick M, Schnyder U, Bryant RA, Morina N. Comorbidity of posttraumatic stress disorder and depression in tortured, treatment-seeking refugees. J Trauma Stress. 2017;30(4):409-15.

81. Karam EG. Comorbidity of posttraumatic stress disorder and depression. In: Fullerton C, Ursano RJ, editors. Posttraumatic stress disorder: Acute and long-term responses to traumas and disaster. Washington DC: American Psychiatric Press; 1997. p. 77-90.

82. Fazel $\mathrm{M}$, Wheeler J, Danesh J. Prevalence of serious mental disorder in 7000 refugees resettled in western countries: a systematic review. Lancet. 2005;365(9467):1309-14

\section{Submit your next manuscript to BioMed Central and we will help you at every step:}

- We accept pre-submission inquiries

- Our selector tool helps you to find the most relevant journal

- We provide round the clock customer support

- Convenient online submission

- Thorough peer review

- Inclusion in PubMed and all major indexing services

- Maximum visibility for your research

Submit your manuscript at www.biomedcentral.com/submit
Biomed Central 